\title{
POTENCIAL ENZIMÁTICO DOS FUNGOS ENDOFÍTICOS NA PRODUÇÃO DE BIOCOMBUSTÍVEIS
}

\section{ENZYMATIC POTENTIAL OF ENDOPHYTIC FUNGI IN BIOFUELS PRODUCTION}

Luiz Renato Lima Silva Miranda ${ }^{1}$ (D), Luis Flávio Nogueira de Souza ${ }^{1}$ (D), Vanuza de Sales

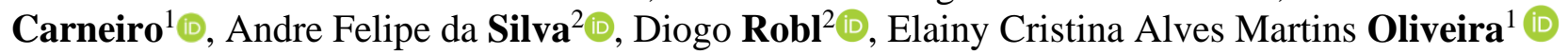

${ }^{1}$ Universidade Federal do Tocantins, Gurupi, TO, Brasil.

${ }^{2}$ Universidade Federal de Santa Catarina, Florianópolis, SC, Brasil.

biocris@mail.uft.edu.br

\section{RESUMO}

A crescente demanda por energias renováveis promovem a produção de biocombustíveis por meio da utilização de biomassas, o bioetanol e biodiesel são matrizes energéticas eco-sustentáveis. Embora sua composição seja variada de acordo com a sua origem, as biomassas quando submetidas a pré-tratamentos adequados são blocos químicos para produção de enzimas. A capacidade dos fungos endofíticos colonizarem ambientes suscetíveis a constantes interações metabólicas os tornam candidatos favoráveis na produção de enzimas extracelulares com potencial aplicação na produção de biocombustíveis, uma vez que são aplicados como pré-tratamento biológico de biomassas. Neste contexto, esta revisão contextualiza as fontes de biomassas e recolhe dados sobre estirpes fúngicas endofíticas e técnicas moleculares e de bioprocessos para o rastreio e produção de enzimas. Nós objetivamos evidenciar o atual cenário dos fungos endofíticos e suas enzimas para desconstrução da biomassa lignocelulósica e para catalise da reação de esterificação, bem como as etapas do processo produtivo de etanol e biodiesel, respectivamente.

Palavras-chave: Bioetanol. Biodiesel. Biomassa lignocelulósica. Bioprocessos. Fungos endofíticos.

\begin{abstract}
The growing demand for renewable energy has stimulated the production of biomass-derived biofuels, with bioethanol and biodiesel forming eco-sustainable energy matrixes. Although the composition is highly origin-dependent, when subjected to appropriate pretreatment, biomass can provide a chemical basis for enzymes production. Endophytic fungi are commonly applied to biomasses as biological pre-treatments. Their ability to colonize environments undergoing constant metabolic interaction makes them favorable candidates for the production of extracellular enzymes with potential application in biofuels production. This review contextualizes biomass sources and provides a bibliographic survey of studies of endophytic fungal strains and molecular and bioprocess techniques for enzyme screening and production. The current study summarizes current knowledge of digestion of lignocellulosic biomass with endophytic fungi-derived enzymes and their capacity for catalyzing the esterification reaction, for ethanol and biodiesel production, respectively.
\end{abstract}

Keywords: Bioethanol. Biodiesel. Bioprocesses. Endophytic fungi. Lignocellulosic biomass. 


\section{INTRODUÇÃO}

A crescente preocupação com as questões ambientais e a conscientização mundial sobre a promoção do desenvolvimento em bases sustentáveis tem estimulado a realização de pesquisas de desenvolvimento tecnológico que visam a utilização de forma eficiente das fontes de energia renováveis, como a biomassa, que têm papel fundamental no contexto energético, ambiental e socioeconômico (LI et al., 2020). O consumo de produtos de origem ou síntese química, está sendo reduzido de acordo com o maior desenvolvimento de tecnologias verdes aplicadas na conversão enzimática de biomassas (ADSUL et al., 2020).

Biomassa é uma fonte de energia química armazenada como matéria orgânica de origem vegetal, animal e/ou microbiana que pode ser utilizada para produção de biocombustíveis como bioetanol e biodiesel (ZHU et al., 2020). A conversão enzimática destas biomassas não exige condições de altas temperaturas e valores extremos de $\mathrm{pH}$, o que favorece o seu uso na indústria em contrapartida a catálise química (OLIVEIRA et al., 2012; HWANG et al., 2014).

Fábricas produtoras de etanol lignocelulósico tem se desenvolvido em grande escala comercial no Brasil (Raízen) e EUA (POET-DSM Advanced Biofuels), o primeiro usando hidrolisados de bagaço-de-cana e o segundo, a palha do milho (GHD, 2019). Por outro lado, o biodiesel é uma alternativa renovável, compatível com os motores diesel comerciais e sua produção em larga escala é restrita devido aos elevados custos e competição da matéria-prima por alimentos, como óleos comestíveis (ATHAR; ZAIDI, 2020; HAMZA et al., 2020). Em contrapartida, os fungos endofíticos foram relatados como potencial fonte lipídica para produção de biodiesel (DEY; BANERJEE; MAITI, 2011; PAUL et al., 2020), assim como, produzem enzimas aplicadas à etapas do processo produtivo de bioetanol e biodiesel (ROBL et al., 2013; ROBL et al., 2015; ROCHA et al., 2020).

Os endofíticos colonizam assintomaticamente de forma sistêmica o apoplasto, vasos condutores e interior de tecidos vegetais, como folhas, caule, raízes, frutos e sementes (RODRIGUEZ et al., 2009; ROCAFORT et al., 2020). Eles desempenham papel ecológico no ambiente com a adaptação de sua fisiologia para produção de metabólitos ativos que possibilitam a sua colonização (SCHULZ et al., 2002), uma vez que podem excretar glicohidrolases e oxidoredutases que promovem a sua penetração e desenvolvimento no interior do hospedeiro (CORRÊA et al., 2014). Recentemente, o endofítico Fusarium oxysporum foi relatado como produtor de celulase $(2,88 \mathrm{IU} / \mathrm{mL})$; lacase $(0,57 \mathrm{IU} / \mathrm{mL})$; lignina peroxidase $(8,43 \mathrm{UI} / \mathrm{mL})$ e bioetanol $(2,47 \mathrm{~g} / \mathrm{L})$ com rendimento de $0,84 \mathrm{~g} / \mathrm{g}$ em um bioprocessamento consolidado (M'BAREK et al., 2020).

Neste contexto, esta revisão objetiva contextualizar o uso de biomassas e pré-tratamentos biológico/enzimático aplicados a conversão desta em fonte de energia, assim como, estudos sobre bioprospecção, otimização e genômica de fungos endofíticos potencialmente produtores de enzimas aplicadas à produção de bioetanol e biodiesel.

\section{METODOLOGIA}

Para uma pesquisa de dados abrangente, a aquisição de dados é uma etapa importante e os bancos de dados para esta pesquisa foram Google Acadêmico, Science Direct e Periódicos Capes. Os manuscritos foram selecionados entre o período de 2002-2020 publicados preferencialmente em língua inglesa, disponível para livre acesso e que corroborasse com a proposta deste estudo. As palavras-chave para pesquisar artigos importantes incluíram "energia renovável", "produção de etanol", "produção de biodiesel", "fungos endofíticos", "lipases", "bioprocessos", "pré-tratamento biológico", "hidrólise enzimática", "sacarificação" e itens relacionados. 


\section{DESENVOLVIMENTO}

\section{Biomassas e enzimas aplicadas a produção de biocombustíveis}

A utilização de biomassas tem sido destaque no mercado internacional, sendo considerada uma das principais alternativas para a diversificação da matriz energética e a consequente redução da dependência dos combustíveis fósseis (GHD, 2019; ZHU et al., 2020). A produção de etanol e biodiesel usando biomassas, apresenta vantagens devido ao uso de matéria-prima renovável, disponibilidade (dependente de fatores sazonais) e promove o ciclo zero do carbono (MANOCHIO et al., 2017).

Lipídios produzidos por microrganismos oleaginosos têm sido relatados como biomassa microbiana promissora a produção de biodiesel, devido à sua alta composição em relação ao peso seco da biomassa total e possuir atributos superiores, por exemplo, propriedades físico-química desejáveis de matéria-prima para produção e emprego do biodiesel final produzido (DEY et al., 2011; PAUL et al., 2020). Por outro lado, biomassas vegetais aplicadas a produção de etanol são produzidas por fotossíntese através da captura da energia solar e armazenamento na forma de células e/ou polímeros de parede vegetal, uma vez que estes polímeros podem ser compostos de armazenamento (por exemplo, amido) ou parede celular de polissacarídeos (por exemplo, celulose) (ROBL et al., 2013; MANOCHIO et al., 2017).

Fontes de biomassa lignocelulósica e amido são promissoras para produção de bioetanol, esta última ainda não compete com a demanda global devido ao seu valor primário como alimento (por exemplo, milho/batata) (GUPTA; VERMA, 2015). A biomassa lignocelulósica é composta por celulose (40-50\%), hemicelulose (20-30\%) e lignina (10-25\%). As interações entre estes polissacarídeos, assim como as suas interações com lignina, formam barreiras físicas que dificultam à disponibilidade e acessibilidade das enzimas a estes substratos (MOOD et al., 2013). A recalcitrância da biomassa, cristalinidade da celulose e a composição heterogênea de hemicelulose, implicam a aplicação de pré-tratamentos físico-químicos e/ou enzimáticos (RASTOGI; SHRIVASTAVA, 2017; LIU et al., 2019). Além disso, a biomassa vegetal apresenta composição variável de acordo com a sua fonte e origem, uma vez que seus constituintes dependem de seu tipo, espécie e uniformidade (SOUZA, et al., 2013; COLLINS et al., 2014). Portanto, há um aumento no interesse em se formular coquetéis enzimáticos específicos para a degradação de biomassa (ROBL et al., 2013; ADSUL et al., 2020).

Sabe-se que as classes das enzimas produzidas por microrganismos variam de acordo com o substrato disponibilizado e metabolizado no cultivo (PAULA et al., 2019). As enzimas microbianas aplicadas a conversão das biomassas são produzidas por cultivo em meio líquido ou em substratos sólidos. O cultivo em meio líquido proporciona melhores condições de variáveis do processo como $\mathrm{pH}$, temperatura e facilidade para recuperar as enzimas extracelulares (NAJAFPOUR, 2015; BEHERA; RAY, 2016). O cultivo sólido simula o ambiente natural dos fungos filamentosos e proporciona contato direto entre o microrganismo e substrato; assim como, a menor quantidade de água disponível possibilita maiores concentrações das enzimas (SOCCOL et al., 2017). No entanto, a homogeneidade dos parâmetros de transferência de massa/calor e controle de processo, assim como, a falta de projetos de biorreatores eficientes e modelos matemáticos são fatores que ainda dificultam a industrialização do cultivo em estado sólido (ARORA et al., 2018).

\section{Pré-tratamento enzimático e biológico aplicados em biomassa vegetal}

Processos de pré-tratamentos quando aplicados em condições ideais promovem a solubilização e/ou fracionamento de um ou mais componentes da biomassa vegetal; facilitam a conversão enzimática (DEMIRBAS, 2005); evitam a degradação de derivados da hemicelulose e possibilitam a recuperação da lignina para conversão em bioprodutos (SINGH et al., 2015). 
Processos enzimáticos produzem menor quantidade de subprodutos residuais, apresentam estabilidade em solventes orgânicos, propiciam produtos com melhor qualidade (LIU et al., 2019), podem ser conduzidos em variações de temperatura e $\mathrm{pH}$ de acordo com as faixas ideais da catálise, não provoca a corrosão em reatores e não gera inibidores em comparação a hidrólise química (RASTOGI; SHRIVASTAVA, 2017). Estratégias como a imobilização do biocatalisador para aumento de tempo de vida e estabilidade, assim como o reciclo da enzima, tem sido relatado para diminuir custos envolvidos na produção destas (OLIVEIRA et al., 2012; 2020).

O pré-tratamento biológico pode consistir na utilização de fungos para melhoria do processo de sacarificação, uma vez que esses microrganismos possuem o maquinário enzimático adequado para desconstruir a biomassa vegetal e liberar açúcares simples para uso na produção de energia (PRAJAPATI et al., 2018). As linhagens endofíticas de Ulocladium sp., Hormonema sp. e Trametes sp. aplicados na sacarificação da madeira de Eucalyptus globulus aumentaram a produção de açúcar em 8,5, 8,0 e 6,0 vezes, respectivamente (MARTÍN-SAMPEDRO et al., 2015).

\section{Hidrólise enzimática aplicada a biomassa vegetal para produção de bioetanol}

O bioetanol é produzido a partir da fermentação alcoólica de monossacarídeos provenientes da hidrólise enzimática de biomassa lignocelulósica ou amilácea, uma vez que o hidrolisado obtido é fonte de glicose e/ou xilose para os microrganismos, na produção de bioetanol (MANOCHIO et al., 2017; LIU et al., 2019).

A hidrólise enzimática requer a ação cooperativa de enzimas que atuam sinergicamente para a desconstrução da celulose (endoglucanases, celobiohidrolases, $\beta$-glucosidase), hemicelulose (xilanases, mananases, $\beta$-xilosidases, $\beta$-manosidases, $\alpha$-arabinofuranosidases, $\alpha$-galactosidases, acetilxilanoesterase, feruloil esterases, $\mathrm{p}$-cumarilesterasese $\alpha$-glucuronidase) e lignina (manganês peroxidase, lignina peroxidase e lacases) (VALENCIA; CHAMBERGO, 2013; SHUBHA; SRINIVAS, 2017). A atividade enzimática pode variar amplamente entre as linhagens microbianas dos endófitos (MARQUES et al., 2018), uma vez que a produção de glicohidrolases está intimamente relacionada à natureza da fonte de carbono e o metabolismo fúngico é influenciado pela composição do meio. Cada linhagem possui um perfil metabólico distinto, enquanto o perfil enzimático também é distinto e depende do meio e do tempo de cultivo (ROBL et al., 2013).

A triagem de fungos endofíticos produtores de enzimas comumente é realizada pelo cultivo sólido em meios contendo substratos específicos para cada enzima (ROBL et al., 2013; CORRÊA et al., 2014). Apresentaremos espécies de fungos endofíticos triados em meio sólidos para produção de enzimas aplicadas a desconstrução de biomassa vegetal.

Em relação a excreção de glicohidrolases, os isolados de hastes e folhas das plantas Syzygium aromaticum, Withania somnifera e Ocimum basillicum excretaram amilase e celulase (KAPOOR et al., 2018). Das linhagens isoladas da planta Cymbidium aloifolium, 80\% produziram celulase, $70 \%$ amilase, $63,33 \%$ protease, $30 \%$ pectinase e $23,33 \%$ lipase (SHUBHA; SRINIVAS, 2017). Endofíticos fúngicos dos gêneros Diaporthe, Saccharicola, Bipolaris e Phoma isoladas de Luehea divaricata, Trichiliaelegans, Sapindussaponaria e Saccharum sp. excretaram amilase, celulase e pectinase (ALBERTO et al., 2016). Neste contexto, enzimas lignases também foram excretadas por endofíticos de guaranazeiro (Paullinia cupana var. sorbilis) e de plantas de manguezal (Rhizophoramangle).

Atividade enzimática dos endofíticos tem sido relatada em cultivo submerso como estratégia para triagem. Phyllosticta capitalensis isolado de Hevea brasiliensis produziram arabinase $(944,18$ $\mathrm{U} / \mathrm{mL})$, celulase $(27,10 \mathrm{U} / \mathrm{mL})$, xilanase $(10,85 \mathrm{U} / \mathrm{mL})$, pectinase $(465,47 \mathrm{U} / \mathrm{mL})$ e lacase $(35,68$ $\mathrm{U} / \mathrm{mL}$ ) em meio suplementado com palha e flores de lavanda (WIKEE et al., 2017), assim como, Rhizoctonia sp. e Chaetomium sp. isolados das plantas medicinais Citrus limon e Magnoliachampaca, produziram $(4,1 \mathrm{U} / \mathrm{mL})$ e $(3,7 \mathrm{U} / \mathrm{mL})$ de amilase, respectivamente (PATIL et al., 2015). 
Diversas estratégias têm sido realizadas para melhoria das condições de cultivos líquidos e sólidos, com o objetivo de reduzir custos da produção enzimática através do uso de resíduos agroindustriais. (DELABONA et al., 2012; ROBL et al., 2015; MARQUES et al., 2018). Trichoderma harzianum (isolado de plantas da floresta amazônica) cultivado em glicerol e induzidos com bagaço de cana pré-tratado, em biorreator, produziram celulase (2,27 FPU/mL), xilanase $(106,40 \mathrm{IU} / \mathrm{mL})$ e $\beta$-glucosidase $(9,04 \mathrm{IU} / \mathrm{mL})$ (DELABONA et al., 2016). A linhagem Aspergillus níger DR02 (isolado de Platanus orientalis) apresentou atividade máxima em $120 \mathrm{~h}$ para xilanase $(4,5 \mathrm{IU} / \mathrm{mL})$ e $\beta$-glucosidase $(1,16 \mathrm{IU} / \mathrm{mL})$ em cultivo submerso usando bagaço de cana-de-açúcar deslignificado, pré-tratado e farelo de soja (ROBL et al., 2013). Aspergillus fumigatus (isolado da floresta Amazônica) cultivado em diferentes resíduos agroindustriais, apresentou atividades enzimáticas máximas para endoglucanases CMCase (160,1 IU/g), celulase total FPase (5,0 FPU/g), $\beta$-glucosidase $(105,82 \mathrm{IU} / \mathrm{g})$ e xilanase $(1.055,62 \mathrm{IU} / \mathrm{g})$ (DELABONA $e t$ al., 2012).

Técnicas de Fed-batch foram relatadas para obter maiores quantidades de produto em cultivos submersos e superar a inibição do substrato ou limitação de oxigênio (ou ambos) em biorreatores (ROBL et al., 2015; OCHOA, 2019). A. niger DR02 cultivado em licor rico em pentoses do pré-tratamento hidrotérmico do bagaço de cana-de-açúcar e com diferentes estratégias de alimentação, apresentou atividades máximas de xilanase com alimentação constante $(458,1$ $\mathrm{U} / \mathrm{mL})$, exponencial $(428,1 \mathrm{U} / \mathrm{mL})$ e exponencial pulsado $(264,37 \mathrm{U} / \mathrm{mL})$ (ROBL et al., 2015).

$\mathrm{O}$ uso de ferramentas estatísticas foi aplicado para produção de $\beta$-glucosidase $(7,41 \mathrm{U} / \mathrm{mL}$ em $144 \mathrm{~h})$ e pectinase $(5,32 \mathrm{U} / \mathrm{mL}$ em $48 \mathrm{~h})$ a partir de Annulohypoxylon stygium, no qual o design de experimentos permitiu a otimização de meios de cultura a partir da polpa cítrica $(20 \mathrm{~g} / \mathrm{L})$, farelo de soja $(20 \mathrm{~g} / \mathrm{L})$ e sacarose $(2,42 \mathrm{~g} / \mathrm{L})$ (ROBL et al., 2015). Endofíticos Botryosphaeria sp. e Saccharicola sp. EJC04 tiveram atividade enzimática de endoglucanases e $\beta$-glicosidases aumentada em 95\% e 30\%, respectivamente, após a melhoria das condições de cultivo por planejamentos experimental. Além disso, as características bioquímicas das endoglucanases e xilanases são adequadas para sacarificação do bagaço de cana pré-tratado, uma vez que sacarificação enzimática do bagaço-de-cana resultou em glicose $(3,66 \mathrm{~g} / \mathrm{L})$ e xilose $(1,66 \mathrm{~g} / \mathrm{L})$ (MARQUES et al., 2018).

Métodos moleculares são comumente aplicados para seleção do perfil enzimático de endofíticos (GIANOULIS et al., 2012; ROBL et al., 2015; WU et al., 2017). O perfil transcricional de Ascocoryne sarcoides mostrou 1.435 genes expressos quando cultivados em fontes de carbono como celulose, celobiose e dextrose de batata. Outros genes foram expressos exclusivamente em celobiose (398) e celulose (380), o que demonstra as plasticidade metabólicas e fisiológicas desse fungos para utilizar um dissacarídeo solúvel e um polímero insolúvel (GIANOULIS et al., 2012). A mineração do genomas de Hypoxylon sp. CI4A, Hypoxylon sp. EC38, Hypoxylon sp. CO27 e Daldinia eschscholzii EC12 permitiu concluir que estes são produtores de glicohidrolases e lignases, estes dados também foram confirmados pela atividade enzimática de endoglucanases, exoglucanases e $\beta$-glicosidases quando as cepas foram cultivadas em meio de cultura (WU et al., 2017). A composição do secretoma de qualquer espécie de fungo filamentoso depende das características biológicas do microrganismo e varia continuamente em resposta às mudanças nas condições ambientais (COLOGNA et al., 2018). A análise proteômica do secretoma de Annulohypoxylon stygium DR47 apresentou famílias de glicidrolases, como GH3, GH18, GH35, GH54 e GH92, nunca antes relatadas para este fungo (ROBL et al., 2015).

\section{Lipases como ferramenta na produção de biodiesel}

O biodiesel é uma mistura de ésteres de ácidos graxos de cadeia longa derivados de uma matéria-prima lipídica. A produção destes ésteres pode ser catalisada por lipases pelo processo de esterificação/transesterificação em que a matéria-prima lipídica reage com um álcool (metanol/etanol) (BHARATHIRAJA et al., 2014). A catalise enzimática é favorecida na presença 
de etanol e alto conteúdo de ácidos graxos livres a temperatura ambiente (HWANG et al., 2014). Algumas aplicações de lipases fúngicas na síntese de ésteres são apresentados na Tabela 1.

Tabela 1 - Reações de esterificação e transesterificação catalisadas por lipases.

\begin{tabular}{|c|c|c|c|c|c|c|}
\hline $\begin{array}{l}\text { Microrganismo } \\
\text { Produtor }\end{array}$ & Reação & Éster & $\begin{array}{c}\text { Meio } \\
\text { reacional }\end{array}$ & $\begin{array}{c}\text { Tempo } \\
\text { (h) }\end{array}$ & $\begin{array}{c}\text { Conversão } \\
(\%)\end{array}$ & Referência \\
\hline Candida rugosa & $\mathrm{T}$ & $\begin{array}{c}\text { Ésteres } \\
\text { metílicos de } \\
\text { óleo de soja }\end{array}$ & Hexano & 30 & 87 & $\begin{array}{l}\text { Xie e Wang, } \\
\quad(2012)\end{array}$ \\
\hline $\begin{array}{l}\text { Penicillium } \\
\text { corylophilum }\end{array}$ & $\mathrm{E}$ & n-butil oleato & $\begin{array}{l}\text { Micelas } \\
\text { reversas }\end{array}$ & 12 & 100 & $\begin{array}{l}\text { Baron et al. } \\
\quad(2005)\end{array}$ \\
\hline $\begin{array}{l}\text { Penicillium } \\
\text { expansum }\end{array}$ & $\mathrm{T}$ & $\begin{array}{l}\text { Ésteres } \\
\text { metílicos de } \\
\text { óleo de } \\
\text { microalgas }\end{array}$ & $\begin{array}{l}\text { Líquido } \\
\text { iônico } \\
\text { [BMIm] } \\
{\left[\mathrm{PF}_{6}\right]}\end{array}$ & 30 & 90,7 & Lai et al. (2011) \\
\hline $\begin{array}{l}\text { Thermomyces } \\
\text { lanuginosa }\end{array}$ & $\mathrm{E}$ & Laurato de etila & $\begin{array}{l}\text { Micelas } \\
\text { reversas }\end{array}$ & 1 & 92 & $\begin{array}{c}\text { Fernandes et al. } \\
\text { (2004) }\end{array}$ \\
\hline Candida rugosa & $\mathrm{E}$ & $\begin{array}{l}\text { Butirato de } \\
\text { butila }\end{array}$ & Heptano & 24 & 50 & $\begin{array}{l}\text { Paula et al. } \\
\text { (2008) }\end{array}$ \\
\hline $\begin{array}{l}\text { Aspergillus } \\
\text { oryzae }\end{array}$ & $\mathrm{E}$ & $\begin{array}{l}\text { Butirato de } \\
\text { isoamila }\end{array}$ & Hexano & 48 & 80 & $\begin{array}{c}\text { Aragão et al. } \\
(2009)\end{array}$ \\
\hline Candida rugosa & $\mathrm{E}$ & $\begin{array}{l}\text { Oleato de } \\
\text { butila }\end{array}$ & iso-octano & 8 & 70 & $\begin{array}{l}\text { Hilal et al. } \\
\text { (2006) }\end{array}$ \\
\hline $\begin{array}{l}\text { Candida } \\
\text { guilliermondi }\end{array}$ & $\mathrm{E}$ & $\begin{array}{c}\text { Oleato de } \\
\text { metila }\end{array}$ & Hexano & 72 & 86 & Oliveira (2013) \\
\hline $\begin{array}{l}\text { Aspergillus } \\
\text { fumigatus }\end{array}$ & $\mathrm{E}$ & $\begin{array}{l}\text { Oleato de } \\
\text { metila }\end{array}$ & Hexano & 9 & 90,9 & Oliveira (2013) \\
\hline $\begin{array}{l}\text { Aspergillus } \\
\text { fumigatus }\end{array}$ & $\mathrm{E}$ & $\begin{array}{c}\text { Ésteres } \\
\text { metílicos de } \\
\text { óleo de } \\
\text { microalgas }\end{array}$ & Hexano & 12 & 98,35 & Oliveira (2013) \\
\hline
\end{tabular}

Notas: T - transesterificação; E - esterificação

Fonte: Adaptado de Oliveira (2013).

Oliveira (2013) sintetizou biodiesel de microalgas e ácido oleico aplicando lipases produzidas pelos fungos Candida guilliermondii e A. fumigatus isolados de folhas de mamona (Ricinus communis L.), respectivamente. C. guilliermondii apresentou conversão de $86 \%$ e A. fumigatus alcançou conversão acima de 98\%, em 12 h de reação. Costa-Silva (2014) avaliando estratégias de imobilização de lipases produzidas pelo fungo endofítico Cercospora kikuchii, obteve rendimento de transesterificação superior a 96,0\% após 72 horas de reação.

As lipases catalisam uma ampla gama de substratos e apresentam estabilidade e atividade em solventes orgânicos. Assim como, pode ser excretada por fungos endofíticos, uma vez que estudos têm sido relatados sobre o rastreio para produção de lipases em meio sólido e sua aplicação em reação de transesterificação de diferentes biomassas lipídicas (OLIVEIRA et al., 2012; SHUBHA; SRINIVAS, 2017; ROCHA et al., 2020). Preussia africana isolado de Handroanthus impetiginosus, cultivado em óleo de algodão apresentou atividade para lipase (5,9 IU/mL) (SOUZA et al., 2018). Nigrospora spp. Aspergillus sydowii e $F$. oxysporum isolados de orquídea Cymbidiumaloifolium produziram $(3,46 \%),(3,18 \%)$ e $(2,67 \%)$ de lipase em meio sólido, 
respectivamente (SHUBHA; SRINIVAS, 2017). Stemphylium lycopersicie e Sordaria sp. isoladas de Humiria balsamifera e Tocoyena bullata, respectivamente, foram aplicados para produção de lipase (máxima atividade obtida $110 \mathrm{IU} / \mathrm{mL}$ ) e promoveram a reação de esterificação para síntese de oleato de etila (ROCHA et al., 2020).

Os endofíticos Penicillium sumatrensee e A. fumigatus isolados de Ricinus communis cultivados em sementes de girassol produziram lipases, a aplicação direta desta biomassa sólida fermentada contendo a enzima no meio reacional (naturalmente imobilizada) promoveu a catálise de esterificação do ácido oleico e apresentou meia-vida de 14 ciclos de reutilização (OLIVEIRA et al., 2020). Além disso, lipases produzidas pelo endofítico C. guillermondi em cultivo submerso quando imobilizadas, aumentaram as taxas da reação de esterificação para síntese de oleato de metila, permitindo também o seu reuso (OLIVEIRA et al., 2012).

\section{CONCLUSÃO}

Foi demonstrado o potencial de fungos endofíticos para produção de enzimas que atuam na desconstrução da biomassa lignocelulósica, amilácea e lipases para catalisar reações de esterificação. Apesar dos endofíticos terem sido comprovados como produtores de enzimas aplicadas a produção de etanol e biodiesel, a maioria dos estudos prospectaram enzimas para bioetanol, a saber, glicohidrolases. A otimização da produção destas enzimas baseados na influência dos constituintes do meio de cultivo e em estratégias de alimentação de cultivo permitiu a melhoria no bioprocessamento de glicohidrolases. Entretanto, esforços não foram investidos em upstream e downstream e scale up da produção dess. Podemos ressaltar que métodos moleculares foram empregados apenas para seleção do potencial enzimático de fungos endofíticos e não para o melhoramento da produção e/ou característica da enzima.

\section{REFERÊNCIAS}

ADSUL, M. et al. Designing a cellulolytic enzyme cocktail for the efficient and economical conversion of lignocellulosic biomass to biofuels. Enzyme and Microbial Technology, v. 133, p. 109442, 2020.

ALBERTO, R. N. et al. Extracellular enzymatic profiles and taxonomic identification of endophytic fungi isolated from four plant species. Genetics and Molecular Research, v. 15, n. 4, p. 1-12, 2016.

ARAGÃO, V. C. et al. Síntese enzimática do butirato de isoamila empregando lipases microbianas comerciais. Química Nova, v. 32, p. 2268-2272, 2009.

ARORA, S.; RANI, R.; GHOSH, S. Bioreactors in solid state fermentation technology: Design, applications and engineering aspects. Journal of Biotechnology, v. 269, n. May 2017, p. 16-34, 2018.

ATHAR, M.; ZAIDI, S. A review of the feedstocks, catalysts, and intensification techniques for sustainable biodiesel production. Journal of Environmental Chemical Engineering, v. 8, n. 6, p. $104523,2020$.

BARON, A. M. et al. A comparative study of the synthesis of n-butyl-oleate using a crude lipolytic extract of Penicillum coryophilumin water-restricted environments. Journal Molecular Catalysis B: Enzymatic, v. 34, n. 1-6, p. 25-32, 2005. 
BEHERA, S. S.; RAY, R. C. Solid state fermentation for production of microbial cellulases: Recent advances and improvement strategies. International Journal of Biological Macromolecules, $\mathrm{v}$. 86, p. 656-669, 2016.

BHARATHIRAJA, B. et al. Biodiesel production using chemical and biological methods - A review of process, catalyst, acyl acceptor, source and process variables. Renewable and Sustainable Energy Reviews, v. 38, p. 368-382, 2014.

COLLINS, S. R. et al. Variation in the chemical composition of wheat straw: the role of tissue ratio and composition. Biotechnology for biofuels, v. 7, n. 1, p. 121, 2014.

COLOGNA, N. M. et al. Exploring Trichoderma and Aspergillus secretomes: Proteomics approaches for the identification of enzymes of biotechnological interest. Enzyme and Microbial Technology, v. 109, n. May 2017, p. 1-10, 2018.

CORREAA, R. C. G. et al. Endophytic fungi: expanding the arsenal of industrial enzyme producers. Journal of Industrial Microbiology \& Biotechnology, v. 41, n. 10, p. 1467-1478, 2014.

COSTA-SILVA, T. A. Produção e imobilização de lipases produzidas pelo fungo endofítico Cercospora kikuchii para aplicações biotecnológicas. 2014. 231f. Tese (Doutorado em Ciências) Faculdade de Ciências Farmacêuticas de Ribeirão Preto - Universade de São Paulo, Ribeirão Preto, 2014.

DELABONA, P. S. et al. Enhanced cellulase production by Trichoderma harzianum by cultivation on glycerol followed by induction on cellulosic substrates. Journal of Industrial Microbiology and Biotechnology, v. 43, n. 5, p. 617-626, 2016.

DELABONA, P. S. et al. Using Amazon forest fungi and agricultural residues as a strategy to produce cellulolytic enzymes. Biomass and Bioenergy, v. 37, p. 243-250, 2012.

DEY, P.; BANERJEE, J.; MAITI, M. K. Comparative lipid profiling of two endophytic fungal isolates - Colletotrichum sp. and Alternaria sp. having potential utilities as biodiesel feedstock. Bioresource Technology, v. 102, n. 10, p. 5815-5823, 2011.

FERNANDES, M. L. M. et al. Hydrolysis and synthesis reactions catalysed by Thermomyces lanuginosa lipase in the AOT/Isooctane reversed micellar system. Journal of Molecular Catalysis B: Enzymatic, v. 30, n. 1, p.43-49, 2004.

GHD. Biofuels and transport: an Australian opportunity. . [S.1.]: Australian Renewable Energy Agency . Disponível em: 〈https://apo.org.au/node/268686>., 2019

GIANOULIS, T. A. et al. Genomic analysis of the hydrocarbon-producing, cellulolytic, endophytic fungus Ascocoryne sarcoides. PLoS Genetics, v. 8, n. 3, p. e1002558, 2012.

GUPTA, A.; VERMA, J. P. Sustainable bio-ethanol production from agro-residues: A review. Renewable and Sustainable Energy Reviews, v. 41, p. 550-567, 2015.

HAMZA, M. et al. A review on the waste biomass derived catalysts for biodiesel production. Environmental Technology \& Innovation, v. 21, p. 101200, 2020. 
HILAL, N. et al. Lipase-immobilized biocatalytic membranes for enzymatic esterification: Comparison of various approaches to membrane preparation. Journal of Membrane Science, v. 268, p. 198-207, 2006.

HWANG, H. T. et al. Lipase-catalyzed process for biodiesel production: protein engineering and lipase production. Biotechnology and bioengineering, v. 111, n. 4, p. 639-653, 2014.

KAPOOR, N. et al. Bio-prospecting fungal endophytes of high altitude medicinal plants for commercially imperative enzymes. Bioscience Biotechnology Research Communications, v. 11, n. 3, p. 370-375, 2018.

LAI, J. Q. et al. Enzymatic production of microalgal biodiesel in ionic liquid [BMIm] [PF6]. Fuel, v. 95, n. 1, p. 329-333, 2011.

LI, L. et al. Review and outlook on the international renewable energy development. Energy and Built Environment, 2020. Disponível em: <http://www.sciencedirect.com/science/article/pii/ S2666123320301148>.

LIU, C. G. et al. Cellulosic ethanol production: Progress, challenges and strategies for solutions. Biotechnology Advances, v. 37, n. 3, p. 491-504, 2019.

MANOCHIO, C. et al. Ethanol from biomass: A comparative overview. Renewable and Sustainable Energy Reviews, v. 80, p. 743-755, 2017.

MARQUES, N. P. et al. Cellulases and xylanases production by endophytic fungi by solid state fermentation using lignocellulosic substrates and enzymatic saccharification of pretreated sugarcane bagasse. Industrial Crops and Products, v. 122, p. 66-75, 2018.

MARTÍN-SAMPEDRO, R. et al. Use of new endophytic fungi as pretreatment to enhance enzymatic saccharification of Eucalyptus globulus. Bioresource Technology, v. 196, p. 383-390, 2015.

M'BAREK, H. N. et al. Consolidated bioethanol production from olive mill waste: Wood-decay fungi from central Morocco as promising decomposition and fermentation biocatalysts. Biotechnology Reports, v. 28, p. e00541, 2020.

MOOD, S. H. et al. Lignocellulosic biomass to bioethanol, a comprehensive review with a focus on pretreatment. Renewable and Sustainable Energy Reviews, v. 27, p. 77-93, 2013.

NAJAFPOUR, G. D. Industrial Microbiology. Biochemical Engineering and Biotechnology, n. February, p. 1-18, 2015.

OCHOA, S. Fed-Batch Fermentation - Design Strategies. Comprehensive Biotechnology. v. 2. p. 586-600. [S.1.]: Elsevier, 2019.

OLIVEIRA, A. C. D. et al. Production of methyl oleate with a lipase from an endophytic yeast isolated from castor leaves. Biocatalysis and Agricultural Biotechnology, v. 1, n. 4, p. 295-300, 2012. 
OLIVEIRA, A. C. D. Síntese enzimática do biodiesel de microalgas a partir de lipases produzidas por fungos endofíticos. 2013. 106f. Dissertação (Mestrado em Engenharia e Ciências dos Materiais) - Universidade Federal do Paraná, Curitiba, 2013.

OLIVEIRA, A. C. D. et al. Production of methyl oleate by direct addition of fermented solid Penicillium sumatrense and Aspergillus fumigatus. Renewable Energy, v. 162, p. 1132-1139, 2020.

PATIL, M. G. et al. Extracellular enzymatic activities of endophytic fungi isolated from various medicinal plants. International Journal of Current Microbiology and Applied Sciences, v. 4, n. 3, p. 1035-1042, 2015.

PAUL, S. et al. Characterization of oleaginous endophytic fungi of biodiesel plants as potential biofuel minifactories. Biomass and Bioenergy, v. 142, n. April, p. 105750, 2020.

PAULA, A. V. et al. Comparação do desempenho de lipase de Candida rugosa imobilizada em suporte hibrido de polissiloxano-polivinil álcool empregando diferentes metodologias. Química Nova, v. 31, n. 1, p. 35-40, 2008.

PAULA, R. G. et al. Engineered microbial host selection for value-added bioproducts from lignocellulose. Biotechnology Advances, Microbial Engineering Biotechnologies, v. 37, n. 6, p. 107347, 2019.

PEIXOTO, J. S. G. et al. Bioprospecção de fungos endofíticos de Paullinia cupana e Rhizophora mangle produtores de enzimas lignocelulolíticas. 4 Encontro de Pesquisa e Inovação da Embrapa Agroenergia: Anais, p. 40-46, 2017.

PRAJAPATI, A. S. et al. Review on Cellulase and Xylanase Engineering for Biofuel Production. Industrial Biotechnology, v. 14, n. 1, p. 38-44, 2018.

RASTOGI, M.; SHRIVASTAVA, S. Recent advances in second generation bioethanol production: An insight to pretreatment, saccharification and fermentation processes. Renewable and Sustainable Energy Reviews, v. 80, p. 330-340, 2017.

ROBL, D. et al. The capability of endophytic fungi for production of hemicellulases and related enzymes. BMC Biotechnology, v. 13, p. 1-12, 2013.

ROBL, D. et al. Enhancing of sugar cane bagasse hydrolysis by Annulohypoxylon stygium glycohydrolases. Bioresource Technology, v. 177, p. 247-254, 2015.

ROBL, D. et al. Xylanase production by endophytic Aspergillus niger using pentose-rich hydrothermal liquor from sugarcane bagasse. Biocatalysis and Biotransformation, v. 33, n. 3, p. 175-187, 2015.

ROCAFORT, M.; FUDAL, I.; MESARICH, C. H. Apoplastic effector proteins of plant-associated fungi and oomycetes. Current Opinion in Plant Biology, v. 56, p. 9-19, 2020.

ROCHA, K. S. C. et al. Lipases of endophytic fungi Stemphylium lycopersici and Sordaria sp.: Application in the synthesis of solketal derived Monoacylglycerols. Enzyme and Microbial Technology, v. 142, n. October 2019, 2020. 
RODRIGUEZ, R. J. et al. Fungal endophytes: diversity and functional roles. The New phytologist, v. 182, n. 2, p. 314-330, 2009.

SCHULZ, B. et al. Endophytic fungi: a source of novel biologically active secondary metabolites. Mycological Research, v. 106, n. 9, p. 996-1004, 2002.

SHUBHA, J.; SRINIVAS, C. Diversity and extracellular enzymes of endophytic fungi associated with Cymbidium aloifolium L. African Journal of Biotechnology, v. 16, n. 48, p. 2242-2247, 2017.

SINGH, J.; SUHAG, M.; DHAKA, A. Augmented digestion of lignocellulose by steam explosion, acid and alkaline pretreatment methods: A review. Carbohydrate Polymers, v. 117, p. 624-631, 2015.

SOCCOL, C. R. et al. Recent developments and innovations in solid state fermentation. Biotechnology Research and Innovation, v. 1, n. 1, p. 52-71, 2017.

SOUZA, I. M. et al. Isolation and screening of extracellular lipase-producing endophytic fungi from Handroanthus impetiginosus. Asian Journal of Biotechnology and Bioresource Technology, v. 4, n. 2, p. 1-10, 2018.

SOUZA, A. P. et al. Composition and structure of sugarcane cell wall polysaccharides: Implications for second-generation bioethanol production. BioEnergy Research, v. 6, p. 564-579, 2013.

VALENCIA, E. Y.; CHAMBERGO, F. S. Mini-review: Brazilian fungi diversity for biomass degradation. Fungal Genetics and Biology, v. 60, n. 2013, p. 9-18, 2013.

WIKEE, S. et al. Lignocellulolytic capability of endophytic Phyllosticta sp. Journal of Bacteriology and Mycology, v. 4, n. 2, 2017.

XIE, W; WANG, J. Immobilized lipase on magnetic chitosan microspheres for transesterification of soybean oil. Biomass and Bioenergy, v. 36, p. 373-380, 2012.

WU, W. et al. Characterization of four endophytic fungi as potential consolidated bioprocessing hosts for conversion of lignocellulose into advanced biofuels. Applied Microbiology and Biotechnology, v. 101, n. 6, p. 2603-2618, 2017.

ZHU, P. et al. New synthetic approaches to biofuels from lignocellulosic biomass. Current Opinion in Green and Sustainable Chemistry, v. 21, p. 16-21, 2020. 